

\section{SOBRE OS AUTORES}

Pedro Arturo Martínez Osorio | pedro.martinez@cecar.edu.co

Lattes: http://lattes.cnpq.br/5320497679443164

Formado em Arquitetura pela Faculdade de Arquitetura da Universidade Católica de Colômbia, Bogotá (2002), Mestre em Educação da Universidade Simón Bolívar, Barranquilla (2012), Doutorando em Design Programa de Pós-Graduação em Design da Faculdade de Arquitetura, Artes e Comunicação - FAAC da Universidade Estadual Paulista, Unesp. Professor Programa de Arquitetura da Corporación Universitaria del Caribe, CECAR, Sincelejo, Colômbia.

Paula da Cruz Landim | paula@faac.unesp.br

Lattes: http://lattes.cnpq.br/4943484003365191

Formada em Arquitetura e Urbanismo pela Faculdade de Arquitetura e Urbanismo da Universidade de São Paulo, FAU - USP (1987), Mestre em Geografia pelo Instituto de Geociências e Ciências Exatas da Universidade Estadual Paulista, Unesp - campus de Rio Claro (1994), Doutora em Arquitetura e Urbanismo pela Faculdade de Arquitetura e Urbanismo da Universidade de São Paulo FAU - USP (2001), estágio de pós-doutorado na Universidade de Arte e Design de Helsinque na Finlândia (2006-2007), Livre-docente em Design de Produto pela Faculdade de Arquitetura, Artes e Comunicação da Universidade Estadual Paulista, Unesp campus de Bauru (2009), professora do Departamento de Design da Faculdade de Arquitetura, Artes e Comunicação - FAAC da Universidade Estadual Paulista, Unesp - campus de Bauru desde 1988 e do Programa de Pós-Graduação em Design da Faculdade de Arquitetura, Artes e Comunicação - FAAC da Universidade Estadual Paulista, Unesp - campus de Bauru desde 2004. Atualmente trabalhando nas seguintes linhas de pesquisa: Desenho do Objeto, Projeto de Mobiliário, História do Design e Teoria e Crítica do Design. Possui diversos artigos publicados em periódicos especializados, trabalhos em eventos, tanto nacionais como internacionais, nas áreas de Arquitetura e Design, assim como livros e capítulos de livros publicados. Possui ainda orientandos de graduação, iniciação científica, mestrado e doutorado na área de Design.

Tomas Queiroz Ferreira Barata | barata@faac.unesp.br

Lattes: http://lattes.cnpq.br/7865768257571169

Professor assistente doutor junto ao Departamento de Design da Faculdade de Arquitetura, Artes e Comunicação - FAAC - Unesp campus de Bauru. Doutor em Engenharia Civil, área de concentração em arquitetura e construção pela Faculdade de Engenharia Civil, Arquitetura e Urbanismo da Universidade Estadual de Campinas (2008), mestre em Arquitetura e Urbanismo, área de concentração em tecnologia do ambiente construído pela Universidade de São Paulo (2001), graduação em Arquitetura e Urbanismo pela Universidade de São Paulo (1993), campus USP - São Carlos. Tem experiência na elaboração de projetos de design, arquitetura e engenharia civil, atuando principalmente nos seguintes temas: desenvolvimento de projeto e produção de mobiliários, equipamentos urbanos, componentes e sistemas construtivos préfabricados em madeira e materiais de fontes renováveis e edificações sustentáveis. 


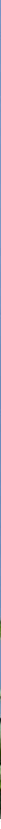

\title{
Conhecimento indígena e processos para o desenvolvimento de produtos de design sustentável com Cana-flecha (Gynerium Sagittatum)
}

\author{
Indigenous Knowledge and process for \\ development of sustainable Design products \\ with Wild Cane (Gynerium Sagittatum)
}

Pedro Arturo Martínez Osorio I Paula da Cruz Landim I Tomás Queiroz Ferreira Barata

\section{Resumo}

Propõe-se uma discussão em torno das possibilidades de desenvolvimento de produtos de Design sustentável a partir da reinterpretação de técnicas tradicionais do artesanato das comunidades indígenas Zenú da Colômbia. Apresentam-se características gerais do material, as principais técnicas indígenas Zenú relativas ao artesanato com cana-flecha, e aspetos relevantes sobre processos de inovação de produtos florestais alternativos com base em Gynerium sagittatum. Identificam-se aspetos muito promissórios na reinterpretação das técnicas tradicionais do artesanato indígena Zenú, para serem aplicadas a processos inovadores no desenvolvimento de materiais e produtos sustentáveis a partir da Gynerium sagittatum. A relação design - artesanato a partir de um foco na autonomia é uma ferramenta para resolver problemáticas complexas em territórios e comunidades tradicionalmente subestimadas aos quais carecem de alternativas possíveis para a construção de seu futuro com dignidade.

Palavras-chave: Design; Sustentabilidade; Conhecimento indígena; Artesanato.

Abstract

It is proposed a discussion about the possibilities of developing sustainable Design products from the reinterpretation of traditional handicraft techniques of the indigenous Zenú communities of Colombia. It presents general characteristics of the material, the main indigenous techniques Zenú related to the crafts with Wild-cane, and relevant aspects on processes of innovation of alternative forest products based on Gynerium sagittatum. Very promising aspects are identified in the reinterpretation of the traditional techniques of Zenú indigenous craftsmanship, to be applied to innovative processes in the development of sustainable materials and products from Gynerium sagittatum. The relation Design - handicrafts from a focus on autonomy is a tool to solve complex problems in traditionally underestimated territories and communities which lack possible alternatives for building their future in dignity.

Keywords: Design; Sustainability; Indigenous knowledge; Handcraft. 


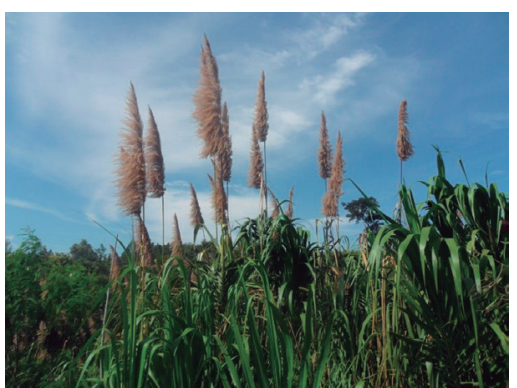

Figura 1: Gynerium sagittatum, conhecida também como Cana-flecha o Cana-brava. Fonte: os autores.

\section{INTRODUÇÃO}

As preocupações sobre problemas ambientais, a sustentabilidade dos processos de produção e a falta de recursos não renováveis tem contribuído, sobre tudo na área do projeto em Design, para criar um debate e buscar alternativas para gerar processos, produtos e serviços sustentáveis, o que pode incluir-se dentro de conceitos como Life Cycle Design e design para a sustentabilidade (MANZINI e VEZZOLI, 2002). Um dos cenários onde ocorre com maior força esse debate é aquele na busca de materiais florestais alternativos como substituição à madeira. Novas perspectivas de utilização das chamadas "novas madeiras" como árvores frutais, coco, caucho, bambu, rattan, palma, outras fibras y resíduos agrícolas, rapidamente tem ganhado importância no mercado, à partir da experimentação e inovação (DURST et al. 2004, 47-53) (PEREIRA e BERALDO, 2008).

A espécie Gynerium sagittatum (Aubl.)p. Beauv. (Figura 1), chamada também "Caña flecha", "Caña brava", "Wild cane", no Brasil é conhecida por muitos nomes populares tais como: "Cana-brava", "Ubá", "Cana-ubá", "Parimá", "Ariná", “Eguará", "Eraī", “Flecha", "Cana-flecha”, "Flecha-de-urubu”, "Canado-rio", "Canarana", "Canarana-flecha", "Cana-amarga", "Capim-uva”, "Cana-selvagem", entre outros (CORADIN et al. 2011, p. 254). É uma erva lenhosa da família Poaceae que se expandem geralmente nos bancos de areia as beiras dos rios, cresce em média 5 a 6 metros de altura, embora existam espécies que podem medir até 14 metros. Tem um colmo de $2-4$ $\mathrm{cm}$ de diâmetro aproximadamente e sua base ou parte inferior é dura e coberta de "cascas", na metade crescem as folhas de forma lanceoladas de 2 a 3 metros aproximadamente, as quais apresentam a borda serrada e afiada, o colmo acaba numa grande inflorescência ou panícula que pode alcançar mais de 1 metro de comprimento, a qual é usada comumente como objeto de decoração (SUÁREZ et al. 2009, p. 5135).

Quanto à sua reprodução, na Gynerium sagittatum é realizado através de tipos tanto sexuais quanto assexuados. A reprodução sexual que é menos comum é feita através das sementes que são agrupadas na inflorescência na forma de panículas que produzem 1,6 milhão de sementes/kg (FRANCIS, 2004, p. 370), as sementes germinam aproximadamente em 3 semanas, as plântulas crescem aproximadamente 20, 30 y 50 centímetros depois de um, dois e quatro meses respectivamente (KALLIOLA et al. 
1992, p. 160). A reprodução assexuada é feita através de rizomas, que são constantemente ativos na produção de novas plantas nos espaços livres em uma distância regular que oscila entre 15-20 centímetros da planta principal (KALLIOLA et al. 1992, p. 160).

É possivel identificar duas variações de Gynerium sagittatum, a "maior", referente àqueles com maior altura, colmo grosso sem ramos e folhas largas e lanceoladas que crescem em forma de ventilador e se desdobram nas suas pontas; a "pequena" devido ao seu tamanho menor, mais esbelto, muitas vezes com hastes ramificadas e folhas lanceoladas rígidas. Também podem se identificar uma terceira variação "média" que apresenta características comuns aos dois tipos principais (KALLIOLA et al. 1992, p. 158).

Na Colômbia, fala-se da existência de 3 tipos de Cana-flecha ou Gynerium sagittatum, que podem corresponder às variações explicadas acima, mas sua diferenciação é determinada de acordo com a qualidade da fibra que oferece para o artesanato, a saber: "palma criolla" de toque suave, que permite um "ripiado" fino e é cultivado principalmente nos estados de Sucre e Córdoba; A "palma martinera" cultivada no estado de Antioquia tem fibra rígida, frágil e mais longa, o que não permite um "ripiado" fino; Finalmente, a "palma costera" que cresce em áreas quebradas e na beira do mar, apresenta uma fibra quebradiça e de má qualidade para a trança.

Atualmente no Brasil, seu uso econômico é muito limitado, especialmente para a fabricação de cercas e redes muito baratas, também a planta pode oferecer forragem regular para gado, mas devido ao seu rápido e ótimo crescimento, dificulta o alcance das folhas mais recentes pelos animais (CORADIN et al. 2011, p. 267).

O seu cultivo é recomendado devido ao potencial da celulose que pode ser utilizada na indústria do papel, bem como as possibilidades oferecidas como fonte para a produção de aglomerados como substitutos da madeira (CONTRERAS et al. 1999). Antigamente os indígenas usavam parte de seu colmo para a elaboração de flechas e instrumentos musicais.

Na Colômbia, seu uso está fortemente associado às tradições indígenas da cultura Zenú, antigos habitantes da costa norte da Colômbia, pois para os descendentes dessas comunidades, é um material muito apreciado 


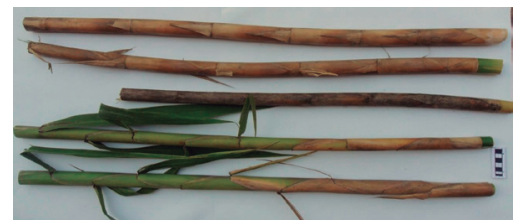

Figura 3: Colmo de Gynerium sagittatum. São observadas pequenas irregularidades no crescimento da planta o qual faz com que seja completamente reta. Fonte: os autores.

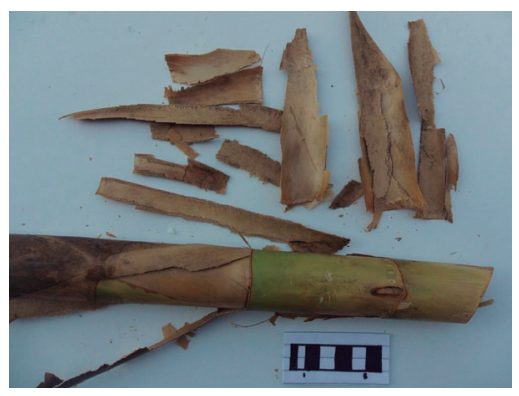

Figura 4: Película da casca que envolve o colmo na parte inferior da planta. Fonte: os autores.

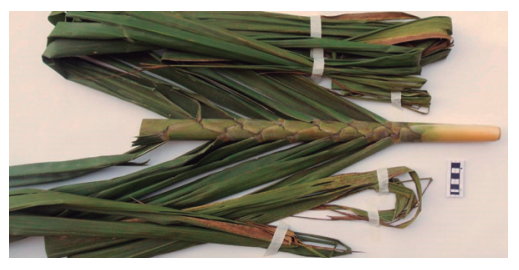

Figura 5: Parte do colmo onde as folhas surgem alternadamente de cada lado. Fonte: os autores. na construção de casas tradicionais com técnica mista ou "bahareque" (SUÁREZ et al. 2009, p. 5135), e especialmente para a elaboração de objetos artesanais, das quais o mais distinto é o chamado "sombrero vueltiao" símbolo do artesanato colombiano no mundo.

\section{CARACTERÍSTICAS GERAIS DA CANA-FLECHA}

São descritas as características de uma espécie de Gynerium sagittatum, coletado na cidade de Agudos, SP, com uma altura total de 8,60 m (Figura 2).

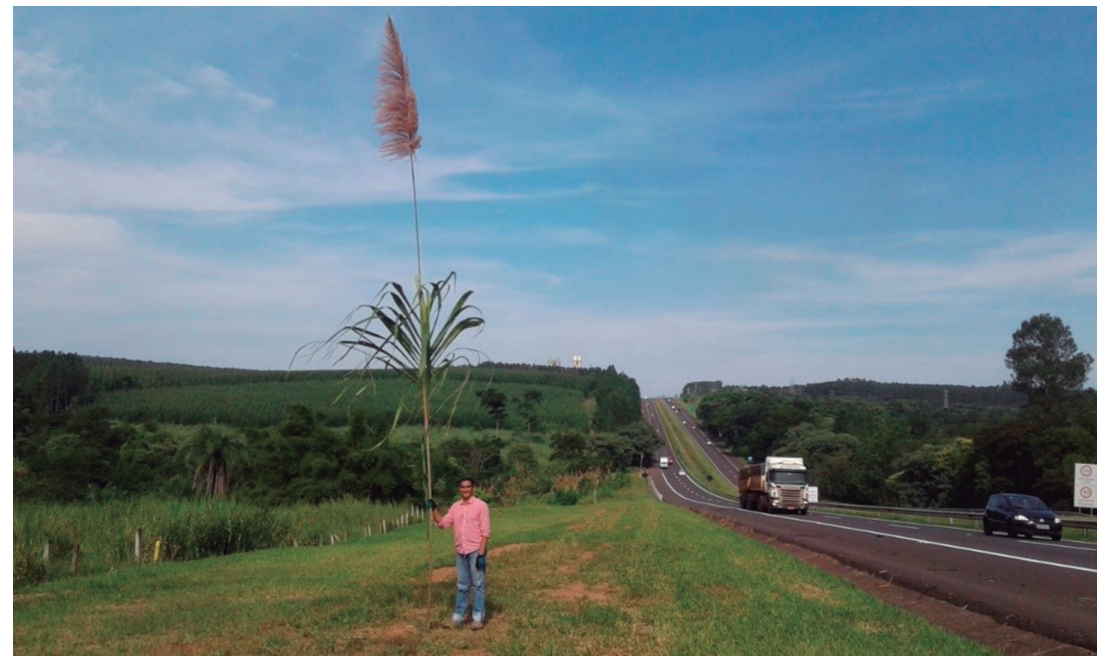

Figura 2: Gynerium sagittatum coletada em Agudos, SP, com uma altura total de $8.60 \mathrm{~m}$. Fonte: os autores.

As raízes são do tipo rizoma dos quais surgem os colmos, algumas raízes laterais também são separadas destas, que são fracas e flexíveis com uma espessura variável de aproximadamente $1 \mathrm{~mm}$ ou menos de diâmetro (FRANCIS, 2004, p. 370).

O colmo é cilíndrico e cresce reto ( 4 cm de diâmetro), embora com pequenas alterações devido às condições particulares em que a planta é encontrada, devido a esta condição pode-se afirmar que ele não é completamente regular (Figura 3). Na sua parte inferior é coberta com um envoltório marrom (Figura 4), que ao alcançar a altura perde sua cor marrom, torna-se cada vez mais verde e aparece de cada lado e alternadamente às folhas (Figura 5). 
O colmo de espécies adultas, reduz progressivamente seu diâmetro para se tornar um eixo central que termina em um ápice que lhe dá a forma de flecha característica de sua inflorescência.

Em seu interior, o caule é conformado por um tecido lignocelulósico que dá a sua rigidez, que enquanto a planta é recém-cortada e o verde é constituído em um enchimento completo do interior muito semelhante à cana-de-açúcar, mas uma vez que a planta tem sido cortada e o processo de secagem da inicio, ele começa lentamente a se contrair, levando o interior a apresentar cavidades irregulares com tecido seco (Figura 6).

As folhas de Gynerium sagittatum são de forma lanceolada (1,70 - 2,0 m), de tipo uni nervura, uma vez que apresentam uma única nervura central grossa e um limbo ou folha de borda serrada ou dentada, o que o torna áspero ao toque (Figura 7). A nervura central é amplamente utilizada na Colômbia por artesãos descendentes do grupo étnico Zenú, que a utilizam como matéria-prima para muitos tipos de artesanato feitos com a trança que é obtida após diferentes processos de preparação.

Uma das características que distinguem a espécie Gynerium sagitattum, é a configuração em que as folhas crescem em grupo de cada lado do colmo. As folhas são de verde escuro e de tipo séssil, ou seja, sem pecíolo e nascem de forma decorrente envolvendo o colmo alternadamente, um após o outro deixando na parte inferior às folhas mais jovens de tamanho menor, e na parte superior as mais antigas e com maior tamanho entre 1,70 - 2,0 m. As folhas maiores quando colocadas na parte superior do grupo, são dobradas produto de seu próprio peso e comprimento, gerando a forma de fã para a visão que é distintiva de sua espécie (Figura 8).

A inflorescência de Gynerium sagittatum é outro dos seus elementos distintivos, é formada pelo prolongamento do colmo, na parte superior do grupo de folhas. 0 colmo, ao reduzir o seu diâmetro, forma um eixo central, o que desencadeia uma panícula de cor ocre amarelo semiescuro que é simplificada em direção ao ápice, ou seja, reduz seu tamanho e número de flores e ramos à medida que se aproxima no final do eixo central (Figura 9).

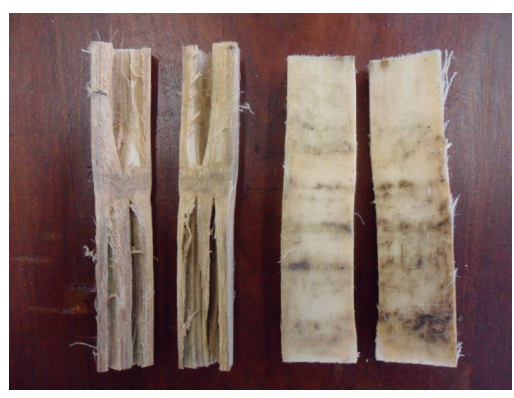

Figura 6: Tecido lignocelulósico de Gynerium sagittatum em processo de secagem e recém-cortado. Fonte: os autores.

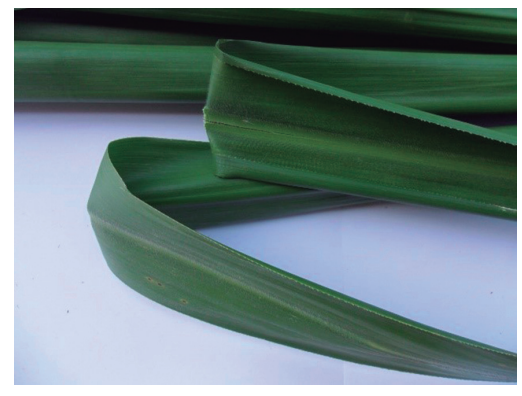

Figura 7: Borda em forma de serra que apresentam as folhas de Gynerium sagittatum. Fonte: os autores.

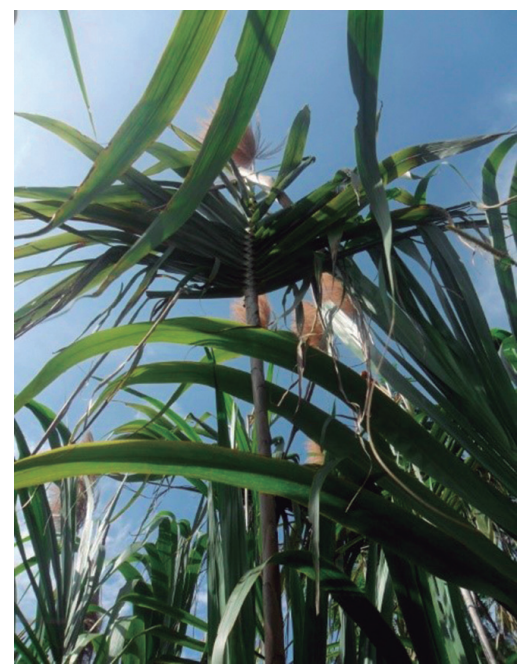

Figura 8: Folhas de Gynerium sagittatum que crescem alternadas abraçando o colmo sem peciolo. Fonte: os autores. 


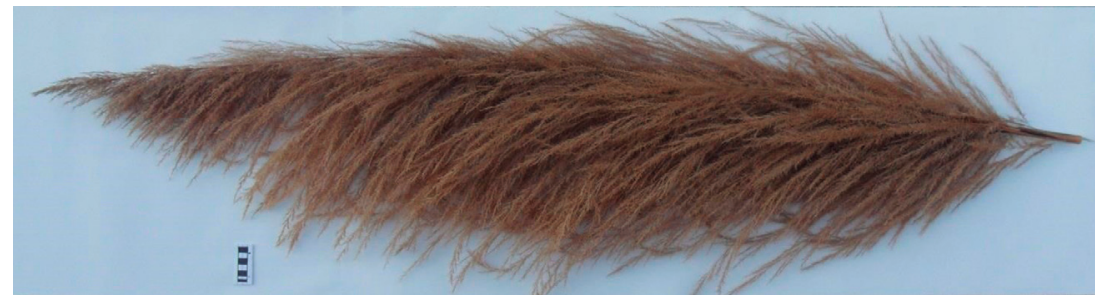

Figura 9: Inflorescência característica de Gynerium sagittatum. Fonte: os autores.

O eixo central juntamente com a panícula constitui um elemento muito visível e característico da espécie que pode medir em conjunto mais de 2,0 m de comprimento. Os frutos que compõem a panícula são estreitos e oblíquos de aproximadamente $1 \mathrm{~mm}$ de comprimento, cobertos com um tipo de cabelo que facilita a sua dispersão através do vento ou da água (KALLIOLA et al. 1992, p. 160).

\section{INVESTIGAÇÕES ASSOCIADAS AO POTENCIAL DA CANA-FLECHA COMO MATERIAL ALTERNATIVO PARA O DESENVOLVIMENTO DO DESIGN DE NOVOS PRODUTOS FLORESTAIS}

São muitas as pesquisas desenvolvidas nos últimos 20 anos sobre as possibilidades oferecidas pela Cana-flecha como material para o desenvolvimento do design de produtos inovadores que podem ser uma alternativa competitiva ao uso da madeira.

É interessante nesse cenário, em primeira parte a pesquisa desenvolvida por Contreras e Owen de Contreras (1997), para a elaboração de um elemento estrutural laminado, tipo parallam, com ripas de Gynerium sagittatum e adesivo fenol-formaldeído. Nessa pesquisa realiza-se um processamento mecânico dos colmos de cana-flecha, para obter ripas com uma espessura media de $3 \mathrm{~mm}$, comprimento $3100 \mathrm{~mm}$ y largura aproximada de $30 \mathrm{~mm}$. Os pesquisadores encontraram valores de testes menores as exigências da norma utilizada como referência, observam uma relação entre a qualidade da línea de cola e os valores baixos obtidos, consideram como negativa a pouca aderência da cola nas ripas quando coincidem com o lado externo impermeável da cana-flecha (CONTRERAS e OWEN de CONTRERAS, 1997, p. 29). 
Contreras e Owen de Contreras (1997), falam dos problemas na elaboração dos elementos estruturais, devido às grandes pressões internas observadas durante o processo de construção das vigas.

Entre as conclusões que Contreras e Owen de Contreras (1997) apresentaram estão a sugestão de desenvolver um estudo semelhante que elimine o fator negativo observado na cutícula impermeável externa, além da necessidade de projetar outro cofragem e sistema de aplicação de pressão na preparação das vigas de forma a consolidar melhor os elementos (p. 35).

Outra pesquisa de grande importância é identificada no trabalho de Contreras et al. (1999), no qual é proposto o desenvolvimento de placas aglomeradas com partículas de Gynerium sagittatum e adesivo de ureiaformaldeído. Nesta pesquisa, os autores desenvolveram testes com placas com 10 e 13\% de resina, com melhor desempenho daqueles com $13 \%$; identificaram fraquezas no processo de produção das partículas com as quais fabricaram as placas, relacionam a baixa resistência do mesmo com as características do moinho e as lâminas, o que fez com que uma grande parte das partículas se tornasse pó, causando uma possível falta de travamento entre as partículas para produzir placas (p. 133).

Os autores também identificam fraquezas na mesma composição física da Cana-flecha, como determinante da baixa resistência, explicam que, na sua estrutura anatômica, a Cana-flecha apresenta duas áreas bem definidas, um parênquima interno e um esclerênquima externo, que define a qualidade do material lignocelulósico da Cana (Contreras et al. 1999, p. 133-134).

Contreras et al. (1999) concluem que as placas desenvolvidas podem ser aplicadas a uma multiplicidade de usos, pois apresentam boa consistência e aparência agradável. Eles recomendam a aplicação de tratamentos contra a umidade e a prevenção de agentes xilófagos para sua posterior produção industrial (p. 129).

Em outro estudo, Contreras et al. (2008), determinam os níveis de sustentabilidade no processo de fabricação de placas com Cana-flecha, usando um método próprio desenvolvido chamado de "método ACVCoclowen". Eles identificam os indicadores negativos mais significativos
O cofragem de metal falhou apesar de ser fabricado com elementos estruturais, sem poder suportar as grandes pressões internas, pois foi apreciado durante a sujeição de pressão que todas as suas faces estavam deformadas (refletindo nas vigas uma vez removidas), com o risco de colapsar a estrutura do cofragem, além da falha contínua dos parafusos que exerceram a pressão constante. Pelo motivo descrito no parágrafo anterior, foi possivel ver em toda a estrutura física das vigas, portanto, nos corpos de prova, que suas faces laterais apresentavam alta porcentagem de espaços vazios. (CONTRERAS O OWEN DE CONTRERAS, 1997, p. 33).

Esta baixa resistência pode ser atribuída ao fato de que nas placas produzidas sob esses parâmetros houve uma má qualidade na produção das partículas com as quais foram feitas, devido à irregularidade de formas e tamanhos obtidos e analisados das espécies de teste que foram obtidos no moinho de laboratório de papel e celulose do LNPF, que é projetado para a fabricação de chips de blocos de madeira sólida. Foi possivel determinar que, devido à má qualidade da afiação da lâmina, a alta velocidade das rotações da lâmina da faca fez com que uma grande parte das partículas se tornasse pó e outras de tamanho médio e irregular, causando uma possivel falta de trava entre as partículas no momento de desenvolver placas. (CONTRERAS et al. 1999, p. 133). 
nos estágios de aquisição do adesivo utilizado, a transformação dos colmos em partículas, peneiração e triagem de partículas, secagem de partículas, colagem, moldagem da placa através da pressão/calor e dimensionamento final da placa (p. 57). Sugerem nas suas conclusões para fazer uso de adesivos mais ecológicos, para aplicar padrões de segurança industrial no estágio de colagem para reduzir os riscos de toxicidade para o operador; para o projeto da indústria, usar resíduos de madeira para alimentar as caldeiras no processo de secagem de partículas (CONTRERAS et al. 2008, p. 58).

Em uma pesquisa recente de Gallego et al. (2014) (GALLEGO, 2014), propõe o desenvolvimento de placas aglomeradas de Cana-flecha, sem o uso de adesivos sintéticos. Eles explicam os potenciais usos da lignina presente em Gynerium sagittatum para substituir os adesivos em placas aglomeradas, propor processos de pré-tratamento, como steam explosion, para o desenvolvimento de placas de partículas de alta densidade de Gynerium sagittatum pressionadas sem o uso de aditivos. Eles identificam uma relação entre os melhores resultados para as propriedades mecânicas e a gravidade do pré-tratamento com steam explosion (GALLEGO et al. 2014, p. 110).

Da pesquisa de Gallego et al. (2014), a redução no uso de adesivos é observada como aspecto positivo, mas considera-se importante analisar a relação do consumo de energia que implica a elaboração do produto através do pré-tratamento e subsequente processo de compressão de calor.

A partir das pesquisas referenciadas, é possivel identificar aspectos ainda a serem melhorados em relação à sustentabilidade dos processos de produção de produtos florestais alternativos com Gynerium sagittatum. Os aspectos relacionados à superação das fraquezas derivadas das características físicas inerentes ao material, a transformação dos colmos, a conformação dos elementos sejam placas ou elementos estruturais, as características de projeto da planta industrial, o tipo de adesivos utilizados e a tipo de recursos energéticos utilizados no processo de produção, são, entre outros, elementos a serem problematizados na busca da inovação desde o Life Cycle Design e o Design para a sustentabilidade. 


\section{CONHECIMENTO DAS COMUNIDADES INDÍGENAS ZENÚ ASSOCIADAS AO PROCESSAMENTO DA CANA-FLECHA}

Há uma grande quantidade de pesquisas sobre os aspectos culturais associados aos processos de produção do artesanato das comunidades indígenas Zenú da Colômbia, para quem a Cana-flecha tem um valor simbólico, uma vez que é uma parte importante da sua visão particular do mundo e sua relação com o território.

Além da sua importância na produção artesanal, a Cana-flecha é apresentada em várias etapas da vida das comunidades indígenas Zenú, também é uma parte importante das tradições culturais de todo o Caribe colombiano. Entre as técnicas construtivas pré-hispânicas ainda prevalecentes, diferentes técnicas construtivas podem ser encontradas a partir das fibras da Cana-flecha, que é usada para a construção de paredes, verticalmente amarradas com videiras e também trançadas como tapetes ou esteiras, especialmente em casas em áreas rurais (LARIOS, 2015, p. 195 em SOLANO et al. 2015). (AGRA, 2016p. 113-115, 119-120).

Um dos documentos que inclui parte do conhecimento indígena Zenú em relação ao processamento da Cana-flecha é a Norma Técnica Colombiana NTC 5714 (ICONTEC, 2009), que compila uma série de processos que fazem parte da cadeia de produção do artesanato elaborado em fibras de Cana-flecha; a fim de estabelecer critérios de sustentabilidade para o uso de um selo ambiental colombiano para esses produtos, e desta forma promover a oferta e demanda de produtos que gerem menos impacto no meio ambiente, como uma ferramenta de comunicação que diferencia os produtos que ter um melhor desempenho ambiental (ICONTEC, 2009, p. i).

A norma NTC 5714 estabelece critérios ambientais, que abrangem praticamente todo o processo de produção artesanal, que vão desde o cultivo da Cana-flecha até a preparação e elaboração dos produtos artesanais e inclui a rotulagem do produto. Entre os processos dos quais a norma fala, destacamos aqueles que fazem parte do conhecimento ancestral das comunidades indígenas Zenú: despaje e desvarite, raspado, blanqueado, ripiado, tinturado e trançado das fibras de Cana-flecha (ICONTEC, 2009, p. 8 -15).
Nosso artesanato em Cana-flecha é um dos principais elementos para defender a nossa identidade cultural, pois com a chegada dos espanhóis em 1492 para a nossa terra, eles pegaram o nosso ouro e nós cortaram a língua se falássemos apenas uma palavra em nosso idioma, então nós os zenúes perdemos o dialeto; mas hoje podemos contar a nossa história no tecido do nosso artesanato, na preparação de nossas refeições ancestrais e naquela relação que temos com o território, com a água, com o vento. Com a lua e todo o universo. (OROZCO, 2013, p. 5). 
Um processo em que a camada vegetal é removida da veia da folha, usando uma faca de borda média. O procedimento é feito colocando o sapato na perna, na qual a fibra é colocada e com a faca é raspada as folhas, este procedimento é repetido quantas vezes for necessário, até que a fibra esteja completamente macia. Este processo é determinante para a qualidade da fibra. (ICONTEC, 2009, p. 9).

Realiza-se em água de Cana agria. Para isso, água limpa suficiente é colocada em um recipiente de acordo com a quantidade de fibra a ser branqueada. Ele pega a Cana agria, removendo a casca ao poste com um facão. A cana descascada é esmagada ou moída em uma superfície dura para liberar o suco e depois espremida na água. $A$ água é agitada e os cachos de Canaflecha são depositados para branquear, colocando o bagaço acima para mantêlo submerso adicionando ácido cítrico, deixando-o na água da Cana agria durante 12 horas ou uma noite.

No dia seguinte, a Cana-flecha é removida, lavada bem com a mesma água, evitando pedaços de bagaço pegajosos, coloque o sol e sereno durante 2 d ou 3d, até que adquira sua cor natural. Evite expor o sol à medida que fica amarelo ou fica sujo com poeira. Caso haja falta de Cana agria, você pode usar laranja ou limão (ICONTEC, 2009, p. 11).

As fibras finas ou "pencas" são feitas de acordo com a qualidade da trança a ser tecida. É importante rasgar o lote inteiro do Cana-flecha que está sendo preparado ao mesmo tempo, pois pode haver diferentes espessuras de corda, a trança não permanecerá uniforme (ICONTEC, 2009, p. 12).
El "despaje e desvarite" consistem em remover a parte larga da folha deixando apenas a nervura central como parte utilizável para a elaboração de artesanato. Este processo é realizado com ferramentas afiadas, além de exigir que ele seja realizado com elementos mínimos de segurança, limpeza pessoal e eliminação de resíduos, que podem ser utilizados como alimentos para animais ou fertilizantes orgânicos (ICONTEC, 2009, p. 8).

O "raspado" consiste no processo de remoção da camada vegetal da nervura central que foi selecionada a partir do "desvarite".

Elementos de segurança, limpeza pessoal e eliminação de resíduos devem ser considerados para este processo, que pode ser reutilizado como fertilizante.

O processo de "blanqueado" ou "branqueamento", como o próprio nome indica, é dar um tom mais claro às fibras de Cana-flecha para uso posterior.

É interessante deste processo o uso de outras espécies de plantas para realizar o branqueamento, bem como a reutilização de água para repetir a mesma atividade e para irrigação de plantas.

O processo de "ripiado" consiste em dividir a fibra em fragmentos mais finos, que condicionarão o tipo de qualidade da trança posterior.

O processo de "tinturado" ou tingimento da fibra começa com a escolha do barro, consiste em aplicar tons diferentes à fibra através do uso de pigmentos vegetais que são adicionados à lama. 0 tom mais tradicional é preto, mas podem ser obtidas cores diferentes do uso de várias espécies, como pigmentos naturais.

Linares et al. (2008), descrevem o processo de "tinturado" das fibras Canaflecha, especificando as espécies de plantas mais utilizadas no processo de tingimento: Cañagria (cogollos de Costus laevis), limón (Citrus limon), naranja agria (Citrus aurantium), dividivi (Caesalpinia coriacea), jagua (Genipa americana) y achiote (Bixa orellana), com folhas de bija (Arrabidaea chica) e cásca ou bacota de plátano (Musa X balbisiana). Eles também explicam que a lama é selecionada a partir de solos sedimentares ricos em substâncias alcalinas (pH 8 a 9) (LINARES et al. 2008, p. 78, 79). 
São interessantes neste processo o uso de pigmentos vegetais e argila do local para realizar o tingimento. A norma técnica sugere o uso de energias limpas se possivel processo de cozimento.

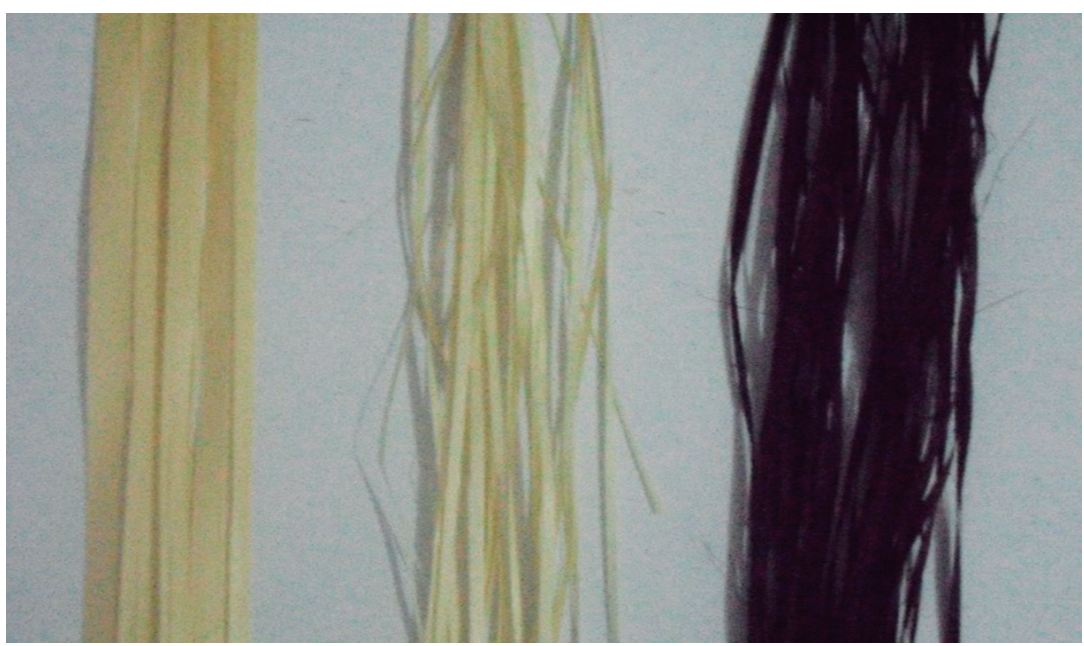

Figura 10: Fibras de Gynerium sagittatum depois do processo de raspado, blanqueado ripiado, e tinturado. Fonte: os autores.

O "trenzado" ou trança é uma das práticas mais tradicionais das comunidades indígenas Zenú, que começa nesta atividade desde uma idade precoce e é mantida ao longo dos anos, transmite esse conhecimento ancestral de geração em geração.

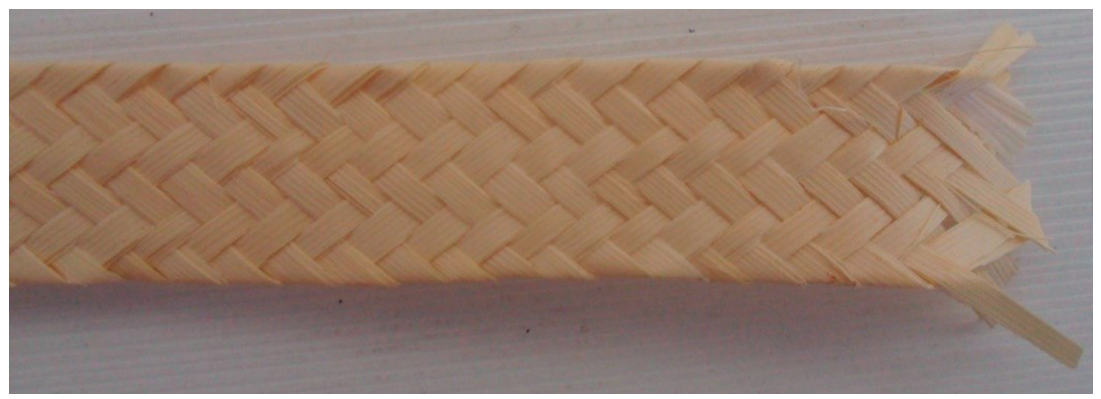

Figura 11: Tecido de Cana-flecha Zenú com cor branco natural, trança feita a partir de folhas de fibras de Gynerium sagittatum. Fonte: os autores.

As diferentes técnicas utilizadas no processamento de Cana-flecha representam um conhecimento ancestral que sobreviveu ao longo do tempo, que tem um forte conteúdo simbólico e cultural, caracterizado por
É escolhido barro de intensa cor preto que não apresente sedimentos. Esta lama é uma lama que pode vir de poços. As características da lama apropriada são que não é pisoteado ou "trajinado" que é preto, que não apresenta areia e não tem veias (que não tem outro tipo de cor que não é preto). A duração da lama é de aproximadamente 6 meses. É necessário ter um recipiente para uso exclusivo para a lama, que é adicionado bija, conchas de banana e outros componentes do tipo vegetal (ICONTEC, 2009, p. 13).

A fibra é introduzida na lama durante $24 h$, é removida e cozida durante $2 h$ com plantas de tintura, sendo a mais utilizada a Bija ou "Limpiadientes"; o processo é repetido duas ou três vezes para obter um bom preto. A fibra não pode durar mais de 3 dias na lama, pois pode deteriorar a fibra. O tingimento é ideal para fazê-lo na fibra "ripiada", mas em muitos casos é feito na trança já tecida (ICONTEC, 2009, p. 14).

A trança é formada com um número impar de conjuntos de peças brancas e pretas denominadas "pares" ou "pés". Este tecido é fundamental para identificar e denominar as diferentes tranças e qualidades do chapéu: 7 pares, "Lica", de 11 "Acotilla"; de 15 "Quinciana", de 19, 21, 23, de 27, sendo mais fino o de maior número de pares de pencas (ICONTEC, 2009, p. 15). 


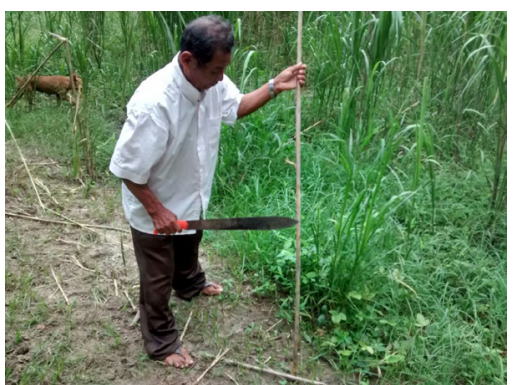

Figura 12: artesao da Colombia no cultivo de Cana- flecha. Fonte: os autores. uma produção harmoniosa com o contexto em que surgiu. Essas técnicas podem ser reinterpretadas no campo do Design para a sustentabilidade, buscando gerar produtos com alto senso de identidade e inovação, diferenciando-se no mercado por sua capacidade de estabelecer processos mais sustentáveis e amigáveis com o contexto natural e cultural.

\section{REFLEXÕES E DISCUSSÕES SOBRE A REINTERPRETAÇÃO DO CONHECIMENTO ARTESANAL INDÍGENA PARA O DESENVOLVIMENTO DE PRODUTOS DE DESIGN SUSTENTÁVEL}

O material, os processos, as técnicas e os conhecimentos anteriormente mencionados possibilitam uma série de reflexões e aspectos interessantes para discutir, em primeira instância sobre a relação cada vez mais estreita entre o Design e o artesanato nos últimos anos.

Dada a necessidade de abrir novas possibilidades de inovação no mundo contemporâneo, o Design tem tido cada vez mais interesse em estabelecer diálogos significativos em diferentes cenários, superar preconceitos, se estabelecer cada vez mais como uma disciplina de síntese, estabelecer sinergias que ajudem a solucionar diferentes problemas em diversos contextos.

Diante dessa abertura que é estabelecida para o Design como uma disciplina integrativa, é interessante discutir quais são as abordagens pertinentes para se estabelecer um diálogo entre o design, artesanato, conhecimento e técnicas ancestrais dos indígenas, em torno do Canaflecha? Como é possível relacionar a Cana-flecha, elemento simbólico de uma cultura e material renovável que pode ser encontrado em toda a América Latina a aspectos da vida cotidiana e tradição indígena e vernácula?

Bonsiepe (2011), propõe o estudo da relação Design e artesanato a partir de cinco abordagens: abordagem conservadora, estetizante, produtivista, culturalista e paternalista. A abordagem conservadora para Bonsiepe (2011) é a que procura proteger o artesão de qualquer influência externa; 
a abordagem esteticista propõe-se como aquela que eleva a arte ao status de arte popular e leva-a como inspiração para novas criações; a abordagem produtivista consideraria o artesão apenas como mão-de-obra barata para desenvolver objetos a serem assinados por um artista ou designer; a abordagem culturalista ou essencialista, como Bonsiepe o chama, considera a produção artesanal como a base para encontrar a verdadeira identidade do design de américa Latina; Finalmente, a abordagem paternalista aproveita as condições das comunidades artesanais, desde uma perspectiva política como beneficiárias de programas de assistência social, ou de uma perspectiva lucrativa, para ter utilidade na intermediação entre produção e comercialização (Bonsiepe, 2011, p. 63).

Das diferentes abordagens propostas por Bonsiepe (2011), a abordagem culturalista ou essencialista é muito interessante, embora Bonsiepe a relate "uma postura romântica que idealiza o suposto passado bucólico" (página 63). Deixando de lado qualquer visão romântica que possa estar imersa na abordagem culturalista, é possível encontrar aspectos muito sugestivos em relação às perspectivas que, desde a sustentabilidade social (McKenzie, 2004) vem desenvolvendo recentemente no campo do Design, juntamente com a inovação.

O Design social e inovação social são conceitos que atualmente tem ganhado interesse nas abordagens recentes como solução aos complexos problemas contemporâneos. Pode-se olhar nestas abordagens, uma relação com o enfoque culturalista do que fala Bonsiepe, mais com um alcance de maior interesse, perto do que o próprio Bonsiepe (2011) propõe como humanismo projetual, ou as capacidades para "interpretar as necessidades de grupos sociais e elaborar propostas viáveis, emancipatórias, em forma de artefatos instrumentais e artefatos semióticos" (p. 21).

O Design social, um conceito em processo de construção por aproximadamente 40 anos com as contribuições de Papanek (1995), Bonsiepe (1978) e outros; hoje, é definida como essa abordagem do Design para o desenvolvimento de práticas participativas como uma solução criativa para problemas complexos, focada no empoderamento das comunidades em que intervém. Um dos aspectos a enfatizar é a forma como os designers contribuem para ativar capacidades, capital social e são integrados com elementos de liderança comunitária (Chen et al. 2016, p. 2).

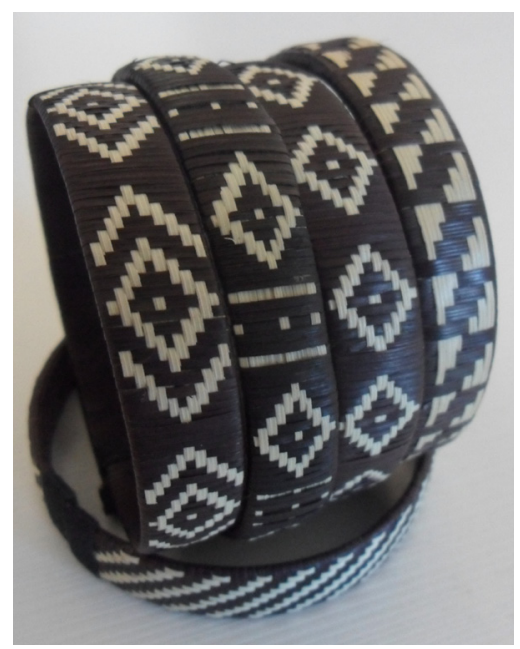

Figura 13: artesanato indigena Zenú da Colombia. Fonte: os autores. 
As inovações sociais são novas ideias, instituições ou formas de trabalho que atendam às necessidades sociais de forma mais eficaz do que as abordagens existentes. Nos nossos dias em todo o mundo, milhões de pessoas estão criando melhores maneiras de responder aos problemas sociais mais desafiadores, como mudanças climáticas, doenças crônicas, exclusão social e pobreza material (Harazin \& Kósi, 2013, p. 28).

\section{O Design autónomo, concebido deste} modo, pode considerar uma resposta ao impulso para a inovação e para a criação de novas formas de vida que surge das luchas, as formas de contra poder e os projetos de vida das ontologias relacionais e comunais ativadas politicamente. (Escobar, 2016, p. 214).
No mesmo sentido, o conceito de inovação social é definido como uma solução inovadora que oferece soluções para as necessidades sociais, de forma mais eficaz, eficiente, sustentável ou justa naqueles lugares onde as administrações não conseguiram alcançar efetivamente (Phills et al. 2008, p. 36).

Recentemente Escobar (2016), engloba os diferentes conceitos associados com as ideias do Design social e inovação social, desde uma nova reorientação ontológica do design, no que chama de design para a autonomia. Caraterizado entre outros aspectos por ter como objetivo a realização do comunal; acolhe o ancestral assim como novos futuros possíveis; privilegia intervenções para o fomento de formas de organização não patriarcal, não liberal, não centrada no Estado e não capitalistas; considera a articulação comunidade - atores sociais tecnologias heterônomas; é aberto a concepções "pluriversales", para prosperar a vida; da esperança à rebelião em defesa dos princípios da vida (Escobar, 2016, p. 214).

Escobar (2016) recolhe de forma interessante o que se pode considerar um enfoque pertinente para estabelecer um diálogo entre o Design, artesanato, conhecimento e técnicas ancestrais dos indígenas, ao redor da Cana-flecha; devido a que articula o respeito pela tradição e o desenvolvimento de novas alternativas na construção de futuros possíveis em harmonia entre o humano e o natural.

Por outra parte, um aspecto de interesse para discutir, se encontra também nas possibilidades do conhecimento indígena, para estabelecer alternativas à inovação de processos e produtos de design sustentável a partir da Cana-flecha.

Nas pesquisas de Contreras e Owen de Contreras (1997), e Contreras et al. (1999), se identifica como uma fraqueza a superar a composição física da Cana-flecha especificamente falando da diferencia entre as camadas internas e externas do colmo. Como alternativa para superar essa fraqueza, é encontrado valor nas técnicas artesanais para o processamento da Cana-flecha desenvolvidas pelos indígenas Zenú, especificamente em seus processos de preparação manual das fibras chamados "despaje - desvarite" y "raspado", o qual ao serem aplicado nas ripas de Gynerium sagittatum como preparação das peças a serem usadas, 
permitiria a eliminação da camada exterior esclerenquimatosa, evitar que a fibra se converta em pó e reaproveitar grande parte da camada interna como fonte de fibra para serem usada na elaboração de produtos sustentáveis por seu alto conteúdo lignocelulósico.

Também Contreras et al. (2008), como conclusões de seu trabalho para determinar niveis de sustentabilidade nos processos de fabricação de chapas de Gynerium sagittatum, encontram dentre outros, indicadores negativos em relação ao adesivo, a transformação dos colmos em partículas e a conformação da chapa, aspectos que podem ser melhorados na pesquisa de Gallego et al. (2014), especificamente em quanto a que esta propõe o desenvolvimento de chapas sem uso de adesivos através do pré-tratamento steam explosión.

Como uma alternativa aos indicadores de sustentabilidade negativos em relação ao adesivo, se acha valor nos trabalhos desenvolvidos com resinas vegetais como o de Belini et al. (2014) e De Lucca (2012), os quais trabalham painéis de partículas de bambu e bagaço de cana de açúcar respectivamente, com resina poliuretana a base de óleo de mamona, eliminando a necessidade de fazer tratamentos que exigem o uso de tecnologias que requeiram maquinarias especializadas como o processo que descrevem Gallego et al. (2014), com o steam explosión, o qual faria viável a transferência de tecnologias à comunidades indígenas e o desenvolvimento de plantas de produção nesses contextos.

A alternativa de usar tecnologias menos poluentes com menor consumo de recursos energéticos no processo de produção, como a inserção dos processos de artesanato indígena Zenú, também contribuiria para gerar indicadores de sustentabilidade positivos para o desenvolvimento de processos de produção de baixo impacto de materiais inovadores como substitutos de madeira a partir da Cana-flecha. Diálogos significativos entre Design e artesanato, neste caso se abrem perspectivas de inovação para o desenvolvimento de produtos de Design sustentável.

\section{CONCLUSÕES PRELIMINARES}

Como conclusões preliminares para a reinterpretação do conhecimento indígena para o desenvolvimento de produtos de Design Sustentável com

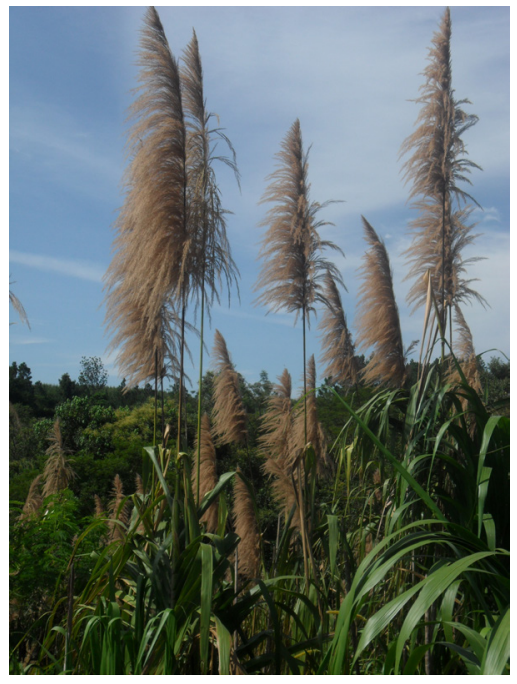

Figura 14: cultivo de Gynerium sagittatum na cidade de Agudos, SP, Brasil. Fonte: os autores. 
Cana-flecha (Gynerium Sagittatum). Em primeiro lugar, é possivel prever um diálogo promissor entre o Design e o artesanato Zenú da Colômbia; que, da perspectiva de um humanismo projetivo, busca o empoderamento e a autonomia de uma comunidade historicamente subestimada por uma visão paternalista que a explorou sem deixar caminhos para um futuro com dignidade.

A inovação e o desenvolvimento de materiais florestais como substituto da madeira é um assunto de grande pertinência e validade na contemporaneidade, especialmente com as espécies consideradas como as novas madeiras. La Cana-flecha dos processos de inovação que tomam como base o diálogo Design e artesanato promete muitas perspectivas interessantes a serem pesquisadas focadas na busca de alternativas ao desenvolvimento de objetos e processos sustentáveis.

Técnicas artesanais relacionadas ao processamento da Cana-flecha, conhecimento ancestral das comunidades indígenas Zenú, abre perspectivas para resolver problemas identificados na pesquisa sobre 0 desenvolvimento de produtos florestais com Gynerium sagittatum. Eles também possibilitam outras inovações devido ao seu baixo impacto ambiental e à redução do uso dos recursos naturais.

Os produtos de design sustentável, desenvolvidos a partir de uma abordagem de autonomia pressupõem um alto grau de identidade e uma grande carga simbólica como artefatos que, além de serem representativos de uma cultura, propõem formas alternativas para sua evolução. Em contraste com as abordagens insustentáveis para o desenvolvimento, que serviu ao Design ao longo da história.

\section{REFERÊNCIAS}

AGRA. Técnicas vernáculas. Programa Paisajes de Conservación. USAID, MINAMBIENTE, Fondo Patrimonio Natural, AGRA Arquitectos (Anzellini García Reyes - Arquitectos), 2016. 168p. Disponível em: https:/www.rds.org.co/es/recursos/tecnicas-vernaculas. Acesso em: 30 abril, 2017.

Bonsiepe, Gui. Design, cultura e sociedade. São Paulo: Blucher. 2011. 270p.

Bonsiepe, Gui. Teoría y práctica del diseño industrial. Elementos para una manualística crítica. Barcelona España: Gustavo Gili. 1978. 258p. 
Contreras, Wilver; Cloquell, Vicente; Owen de C, Mary. Determinación de los niveles de sostenibilidad del proceso de fabricación de tableros de caña brava (Gynerium sagittatum), a partir del método acv-Coclowen. Revista Forestal Venezolana, Año XLII, Volumen 52(1) enero-junio, 2008.p. $47-59$.

Contreras, Wilver; Owen de C, Mary E. Elaboración de un elemento estructural laminado, tipo parallam, con tiras de caña brava Gynerium sagittatum y adhesivo fenol-formaldehído. Revista Forestal Venezolana. Facultad de Ciencias Forestales y Ambientales. Universidad de Los Andes. Mérida, Venezuela 41(1), 1997: 29-36.

Contreras, W; Owen de C, M.E; Garay, D.A; Contreras, Y. Elaboración de tableros aglomerados de partículas de Caña Brava (Gynerium sagittatum) y adhesivo urea-formaldehído. Revista Forestal Venezolana. 43(2) 1999, 129-135.

Coradin, L; Siminski, A; Reis, A. (Eds.). Espécies nativas da flora brasileira de valor econômico atual ou potencial. Plantas para o futuro - Região Sul. Brasilia: MMA, Ministério do Meio Ambiente, 2011.934p.

De León, Andrea Mara Henneberg. La técnica constructiva del bahareque en el estado Zulia. Estudio comparativo. Trabajo de grado especialización en construcción de obras civiles, Universidad Rafael Urdaneta. Maracaibo, 2005. Disponivel em: http:/200.35.84.131/portal/ bases/marc/texto/9110-05-00199.pdf acesso abril 30 de 2017.

De Lucca Sartori, Diogo. Painel portante estrutural com chapa de partículas de bagaço de cana-de-açúcar e resina de mamona para centro de manejo ovino. Pirassununga, SP, 2012. Dissertação de mestrado, Universidade de São Paulo. Disponivel em: <www.teses.usp.br/ teses/.../74/...25092012.../ME7082572COR.pdf> acesso em: 27 agosto, 2017.

Durst, Patrick; Killmann, Wulf; Brown, Chris. Asia’'s new woods. Journal of forestry, 102 (4), 2004:p. 46- 53.

Escobar, Arturo. Autonomía y diseño: La realización de lo comunal. Popayán: Universidad del Cauca. Sello Editorial, 2016. 281p.

Francis, J. (ed.) Wildland Shrubs of the United States and Its Territories: thamnic descriptions. v. 1. San Juan, PR: U.S. Department of Agriculture, Forest Service, International Institute of Tropical Forestry, and Fort Collins, CO: U.S. Department of Agriculture, Forest Service, Rocky Mountain Research Station. 2004, 830p.

Gallego, Giovanna. Tableros sin aditivos a partir de caña flecha (Gynerium sagittatum). Medellín, 2014. Universidad Pontificia Bolivariana. Trabajo de grado en ingeniería Química. Disponível em: <https:/repository.upb.edu.co/bitstream/handle/20.500.11912/3148/Tableros\%20sin\%20 aditivos\%20a\%20partir\%20de\%20la\%20ca\%C3\%B1a\%20flecha.pdf? sequence=1\&isAllowed=y> acesso em: agosto 23, 2017

Gallego, G; Velásquez, J; Quintana, G. Tableros sin aditivos a partir de Gynerium sagittatum. Revista investigaciones aplicadas, v. 8, n. 2, jul - dic, 2014.p. 101-112.

Harazin, P, Kósi, K. Social Challenges: social innovation through social responsibility. Periodica Polytechnica. Social and Management Sciences 21/1 (2013) 27-38. Doi: 10.3311/PPso.2154

ICONTEC. Norma Técnica Colombiana, NTC 5714. Bogotá. Instituto Colombiano de Normas Técnicas (ICONTEC), 2009. Disponível em: <http:/www.minambiente.gov.co/images/normativa/ Otros/NTC/2009/NTC_5714_2009.pdf> acesso em: 25 agosto, 2017.

Kalliola, R; Puhakka, M; Salo, J. 1992. Intraspecific variation, and the distribution and ecology of Gynerium sagittatum (Poaceae) in the western Amazon. Flora (1992) 186: 153-167.

Larios, Paola. Vivienda Vernácula en el Caribe Colombiano: Diversidad dentro de la Unidad. 179 200. Capítulo Em Solano, J. et al. 2015. Nosotros los del Caribe: estudio interdisciplinario sobre la gran cuenca. Barranquilla: Ediciones Universidad Simón Bolivar. 329p. Disponível em: <https:/ www.researchgate.net/publication/298352077> Acesso em: 30 abril, 2017 
Linares, Edgar; Galeano, Gloria; García, Néstor; Figueroa, Yisela. Fibras vegetales utilizadas en artesanías en Colombia. Bogotá. Artesanías de Colombia S.A, Ministerio de Comercio, Industria y Turismo. Instituto de Ciencias Naturales, Facultad de Ciencias - Universidad Nacional de Colombia, 2008. 328p.

Manzini, E, Vezzoli, C. O desenvolvimento de produtos sustentáveis. Os requisitos ambientais dos produtos industriais. São Paulo: Edusp, 2002. 368p.

McKenzie, S. Social sustainability: towards some definitions. Working Paper Series No 27 Hawke Research Institute. University of South Australia, Magill, South Australia, 2004. Disponivel em: http:/w3.unisa.edu.au/hawkeinstitute/publications/downloads/wp27.pdf Acesso em: 10 janeiro, 2017.

Orozco, Norbey. Rescate de las artesanías en caña flecha como practica cultural en la comunidad indigena senu el pando del municipio de Caucasia. Medellín, Universidad de Antioquia, Facultad de Educación. 2013. Trabajo de grado en Licenciatura en Pedagogía de la Madre Tierra. Disponivel em: <http:/ayura.udea.edu.co:8080/jspui/handle/123456789/138>. Acesso em: 24 agosto, 2017.

Papanek, Victor. Arquitectura e design - ecologia e ética. Lisboa: Edições 70. 1995. Re impresión 2007. 288p

Phills, J, Deiglmeier, K, Miller, D. Rediscovering social innovation. Stanford Social Innovation Review. Fall, 2008 (33-43).

Pereira, M; Beraldo, A. 2008. Bambu de corpo e alma. Bauru, SP: Canal 6, 2008. 240p.

Solano, J. et al. 2015. Nosotros los del Caribe: estudio interdisciplinario sobre la gran cuenca. Barranquilla: Ediciones Universidad Simón Bolívar. 329p. Disponivel em: <https:/www. researchgate.net/publication/298352077>. Acesso em: 30 abril, 2017.

Suárez, I.E; Araméndiz, H; Pastrana, I.J. 2009. Micro propagación de caña flecha (Gynerium sagitatum Aubl.). Revista Facultad Nacional Agronomía de Medellin, 62(2): 5135-5143. 